\title{
Viscous methyl cellulose solution thickens gastric mucosa and increases the number of gland mucous cells in mice
}

\author{
Fumiyo Takabayashi $^{1 *}$ and Hirotaka Sekiguchi ${ }^{2}$ \\ 1 Junior College, University of Shizuoka, 2-2-1 Oshika, Suruga-ku, Shizuoka 422-8021, Japan \\ ${ }^{2}$ Graduate School of Agriculture, Kyoto University, Kitashirakawa Oiwake-cho, Sakyo-ku, Kyoto 606-8502, Japan \\ (Submitted 30 May 2012 - Final revision received 21 January 2013 - Accepted 21 January 2013 - First published online 25 February 2013)
}

\section{Abstract}

We have observed a stiffening of the gastric wall in mice following oral administration of viscous methyl cellulose (MC) solution as a vehicle for food chemicals, an effect which has not previously been reported. To further investigate this effect, young male ICR mice ( $n$ 48) were divided into four groups (one control and three experimental groups) of twelve mice each. Experimental groups I, II and III were administered $0.2 \mathrm{ml}$ of $0.5 \%(\mathrm{w} / \mathrm{v}) \mathrm{MC}$ viscous solution/ $\mathrm{d}$ via a stomach tube for 2,3 and 4 weeks, respectively. Stomachs were collected following $12 \mathrm{~h}$ fasting. The weight of the stomach and mucosa of seven mice per group was measured, and the mucosa was used for the measurement of 8-oxo-2'-deoxyguanosine (8-oxodG). Stomach tissue slices from the remaining five mice per group were stained with haematoxylin and eosin to measure mucosal thickness, and were immunostained with an HIK1083 antibody to determine the number of gastric gland mucous cells. The mucosal thickness of the groups administered the MC solution for 3 and 4 weeks, and the size of the HIK1083-immunostained area of the groups administered the MC solution for 2, 3 and 4 weeks were significantly increased $(P<0 \cdot 01)$ compared with those of the control group. The amount of 8-oxodG was not significantly affected. These results indicate that oral administration of viscous MC solution leads to the thickening of the gastric mucosa, which may be related to an increase in the number of gland mucous cells.

Key words: Methyl cellulose: Gastric mucosa: Proliferation

Cellulose ethers including methyl cellulose (MC, CAS-9004-65-5), a type of dietary fibre, have been evaluated as safe for human consumption, though the acceptable daily intake has not been specified ${ }^{(1)}$. The main reason for the evaluation of this dietary fibre as safe is that the digestive tract is unable to absorb it. A viscous MC solution, for example $0.5 \%(\mathrm{w} / \mathrm{v})$ Methyl Cellulose $400 \mathrm{cP}$ Solution, Sterilized ${ }^{\mathrm{TM}}$, may therefore be used as a vehicle for oral administration instead of an edible oil ${ }^{(2)}$. However, it has been reported that the administration of dietary fibre may have a variety of effects, including the induction of a change in mucosal formation in the proximal digestive tract ${ }^{(3-5)}$, the suppression of fat absorption ${ }^{(6,7)}$, an influence on the intestinal flora ${ }^{(8-10)}$, and the induction of an increase in intestinal mucin ${ }^{(11-14)}$ and the number of goblet cells in the small intestine ${ }^{(15,16)}$. These reports have focused on the effects on the formation and function of the digestive tract; there have been few studies regarding changes induced in the stomach. When we used the viscous MC solution as a vehicle for food chemical administration via a stomach tube, we observed that the stomach became stiff and difficult to open evenly. In preliminary experiments, we noted that the gastric mucosa was thickened by the continuous administration of the viscous MC solution. We therefore investigated the effect of viscous MC solution on the stomach mucosa in the present study.

\section{Materials and methods}

A $0.5 \%(\mathrm{w} / \mathrm{v})$ Methyl Cellulose $400 \mathrm{cP}$ Solution, Sterilized ${ }^{\mathrm{TM}}$ was purchased from Wako Pure Chemicals Industries Limited and was used as the viscous MC solution in the present study. The viscosity of this solution, which is available online at http://www.siyaku.com/, was $7.3 \mathrm{mPa} \times$ s. Histofine Mousestain Kit and DAB Substrate Kit were purchased from Nichirei Biosciences, Inc. Porcine serum was purchased from Gibco. HIK1083 reagent was purchased from Kanto Chemical Company, Inc. Proteinase K, nuclease P1, alkaline phosphatase from Escherichia coli and ribonucleases T1 and A were purchased from Sigma Chemical Company.

Abbreviations: 8-oxodG, 8-oxo-2'-deoxyguanosine; MC, methyl cellulose.

*Corresponding author: F. Takabayashi, fax +81 54202 2628, email tkbys@u-shizuoka-ken.ac.jp 


\section{Animals and diet}

Animal studies were performed in compliance with the regulations of the University of Shizuoka. Male ICR mice ( 4 weeks old) were purchased from Japan SLC, Inc. The animals were housed at $23 \pm 2^{\circ} \mathrm{C}$ and in $50-70 \%$ humidity in a room with a $12 \mathrm{~h}$ light $-12 \mathrm{~h}$ dark cycle, and were maintained on an Oriental MF pellet diet (Oriental Yeast Company Limited) and tap water ad libitum. Oriental MF contained the following ingredients (per $100 \mathrm{~g}$ ): $8.0 \mathrm{~g}$ moisture; $23.1 \mathrm{~g}$ crude protein; $4.9 \mathrm{~g}$ crude fat; $5.7 \mathrm{~g}$ crude ash; $2.8 \mathrm{~g}$ crude fibre; $55.5 \mathrm{~g} \mathrm{~N}$-free extract (a detailed composition is available online at http:// www.oyc-bio.jp/pages/animal_products/feed/ingredient). Mice were acclimatised for 1 week before the commencement of the study.

\section{Experimental procedure}

A total of forty-eight mice were divided into four groups: a control group, which was administered $0.2 \mathrm{ml}$ of sterilised water/d for 4 weeks, and experimental groups I, II and III, which were orally administered $0.2 \mathrm{ml}$ of viscous MC solution per $\mathrm{d}$ for 2 , 3 and 4 weeks, respectively. Both water and MC solution were administered via a stomach tube. The administration period for all groups was terminated at 9 weeks of age. An MC solution dosage of $0.2 \mathrm{ml} /$ animal was chosen for the following reasons. First, it had already been observed in a preliminary experiment that a significant difference in body weight between the control and experimental groups was not induced by the $0.2 \mathrm{ml}$ administration. Therefore, it was thought that the experimental results were unaffected even if the dosage was fixed to $0.2 \mathrm{ml} /$ animal. Second, $0 \cdot 2 \mathrm{ml}$ was a sufficiently small dosage compared with a commonly administered oral dosage ${ }^{(17)}$.

Having been fasted for $12 \mathrm{~h}$ after the final MC administration, animals were killed by anaesthesia with diethyl ether. A $12 \mathrm{~h}$ fasting period was used to ensure that the stomach was not overly full, and thus to avoid any potential damage to the gastric mucosa during dissection, which could be caused by pressure between the tweezers and the gastric contents. The stomachs of seven animals from each group were used for the measurement of stomach weight, gastric mucosal weight and the $\mathrm{pH}$ of the stomach contents. After the stomach contents were removed, a larger cut was made and the stomach was rinsed gently with an isotonic $\mathrm{NaCl}$ solution. The mucosa was then scraped using a scalpel. The mucosa was stored at $-80^{\circ} \mathrm{C}$ until the measurement of 8 -oxo- $2^{\prime}$-deoxyguanosine (8-oxodG), a biomarker of tissue oxidative stress. The stomachs of the remaining five animals per group were used for histological analysis.

\section{Histological examination}

Corpus ventriculi obtained from the stomach were immediately fixed in $10 \%$ formalin and cut horizontally into three pieces (cardiac, middle and pyloric), and the pieces were dehydrated with ethanol, cleaned in xylene, embedded in paraffin and cut into $4 \mu \mathrm{m}$-thick slices. From each of the three pieces, three slices were mounted on a glass microscope slide and subjected to haematoxylin and eosin staining. Mucosal thickness was measured every $200 \mu \mathrm{m}$ on the slides, using an Olympus BX60 microscope and a DP20-5 digital camera (Olympus Corporation), and 150 points were measured per slide.

In addition, three slides, prepared as described previously, were randomly selected from each of the control and three experimental groups, and subjected to immunohistochemical staining. Paraffin-embedded sections were dewaxed in xylene and rehydrated with ethanol and PBS, and endogenous peroxidase activity was blocked using $1.3 \%$ (w/v) $\mathrm{H}_{2} \mathrm{O}_{2}-$ methanol solution. Slides were then processed using a Histofine Mousestain Kit and DAB Substrate Kit (Nichirei Biosciences, Inc.). HIK1083 monoclonal antibody medium (a 1:50 mixture of HIK1083 reagent and PBS containing 2\% $(\mathrm{v} / \mathrm{v})$ of porcine serum on a volume basis) was used as a primary antibody. Peroxidase activity was visualised using diaminobenzidine $-\mathrm{H}_{2} \mathrm{O}_{2}$ solution. Counter-staining was performed using haematoxylin. A control experiment was completed, omitting the primary antibody, and no non-specific staining was seen. The monoclonal antibody HIK1083 specifically reacts with the gland mucous cell-derived mucin localised in the gland mucous cells of the corpus, pyloric gland cells and Brunner's gland cells of the duodenum ${ }^{(18,19)}$. The measurement of the size of the HIK1083-stained area was performed using Scion Image software (available online from the National Institutes of Health at http://scion-image. software.informer.com/). An HIK1083-stained area of $250 \mu \mathrm{m}$ in length was measured in the mucosal regions, in each of which the mucosal thickness was approximately equal to the mean value of the control and experimental groups. As a result, twenty-two, fifty-seven, thirty-two and fifty-two measurements from the control group and groups I, II and III were obtained, respectively. The HIK1083-stained area was expressed as a percentage of the mucosal region.

\section{Measurement of 8-oxo-2'-deoxyguanosine}

Measurement of 8-oxodG was carried out using the method of Kaneko et al. ${ }^{(20)}$. Stomach mucosa was homogenised and centrifuged to remove mitochondria. Following hydrolysis by proteinase $\mathrm{K}$, the tissue was hydrolysed by ribonucleases $\mathrm{T} 1$ and A to completely remove RNA. DNA was then extracted using chloroform-isoamyl alcohol and digested by nuclease P1 and alkaline phosphatase. These processes were performed under an Ar atmosphere. The mixture was filtered through an Ultrafree-MC filter (Millipore Company) and the filtrate was applied to an HPLC system with a Symmetry C18 column $(4.6 \times 150 \mathrm{~mm}$; Kanto Chemical Company, Inc.) and an ESA Coulochem II 5200 electrochemical detector (ESA) with a guard cell $5020(400 \mathrm{mV})$ and an analytical cell $5011(350 \mathrm{mV})$. The amount of 8-oxodG is expressed as the molar ratio to $10^{5}$ $2^{\prime}$-deoxyguanosine, which was calculated from absorption at $260 \mathrm{~nm}$ in the same measurement using a UV detector.

\section{Statistical analyses}

Results are expressed as means and standard deviations, and statistical comparisons among groups were carried out 
using Dunnett's test. Analyses were performed using the Pharmaco Analyst software computerised statistical analysis program (Humanlife). $P<0.05$ was considered to be statistically significant.

\section{Results}

Effect of viscous methyl cellulose solution on body weight, food intake, stomach weight, the ratio of mucosal weight:stomach weight, the $\mathrm{pH}$ of the stomach contents and the length and weight of the digestive tract

There were no significant differences between the groups with respect to any of the parameters shown in Table 1 . The administration of $0.2 \mathrm{ml}$ of viscous $\mathrm{MC}$ solution/d via a stomach tube for 4 weeks caused no alteration in body weight, food intake or digestive tract length and weight. However, it was found that the ratio of mucosal weight:stomach weight in groups II and III tended to increase compared with that of the control group, and that there was an apparent difference between the values of groups I and II.

\section{Histological alteration induced by viscous methyl cellulose solution}

The mucosal histology of the stomach sections of the different experimental groups stained with haematoxylin and eosin or the HIK1083 anti-mucin antibody is shown in Figs. 1 and 2, respectively. The thickness of the gastric mucosa and the percentage of the mucosal area stained with HIK1083 are shown in Table 2. The mucosa became thicker as the administration period of the viscous MC solution was extended, and there was a significant difference in thickness between the control group and groups II and III $(P<0 \cdot 01)$. Although mucosal thickness increased with time during the MC treatment, neutrophil invasion was not observed (groups I, II and III).
Moreover, the HIK1083-stained area was very small in the control group, but the size of the HIK1083-stained area increased with increasing duration of $\mathrm{MC}$ administration; a significant increase was shown in the percentage of the HIK1083-stained area between the control group and groups I, II and III $(P<0 \cdot 01)$.

\section{Amount of 8-oxo-2'-deoxyguanosine in the stomach mucosa}

The amount of 8-oxodG in the nuclear DNA of stomach mucosa is shown in Table 2. Although a tendency for the amount of 8-oxodG to decrease was shown as the duration of administration extended, no significant differences were observed compared with the control group.

\section{Discussion}

Methyl cellulose, the methyl diethyl ether of cellulose, is included in the Japanese Pharmacopeia Sixteenth Edition and used as a distension-promoting laxative, and as an additive that increases the viscosity of a food. The safety of MC intake by human subjects was shown in a study that analysed MC intake at a dose of $250 \mathrm{mg} / \mathrm{kg}$ body weight for $23 \mathrm{~d}^{(21)}$. A solution of MC in water is therefore used as a vehicle for oral administration of various compounds in toxicity tests ${ }^{(2)}$. In the present study, administration of a viscous MC solution showed no effect on body weight, food intake, stomach weight, the $\mathrm{pH}$ of the stomach contents or the length and weight of the distal digestive tract in mice (Table 1). These results suggest that $0.2 \mathrm{ml}$ of $\mathrm{MC}$ viscous solution/d is not detrimental to mice at the whole-body level. Moreover, $0.2 \mathrm{ml}$ for a mouse is equivalent to approximately $320 \mathrm{ml}$ for a human ( $60 \mathrm{~kg}$ body weight) or $1.6 \mathrm{~g} \mathrm{MC}$. This is much less than the value shown in 'Dietary Reference Intakes for

Table 1. Body weight, food intake, stomach weight, stomach mucosal weight, ratio of mucosal weight: stomach weight, $\mathrm{pH}$ of the stomach contents and the length and weight of the digestive tract

(Mean values and standard deviations for twelve or seven mice per group)

\begin{tabular}{|c|c|c|c|c|c|c|c|c|}
\hline & \multicolumn{2}{|c|}{ Control } & \multicolumn{2}{|c|}{1} & \multicolumn{2}{|c|}{ II } & \multicolumn{2}{|c|}{ III } \\
\hline & Mean & SD & Mean & SD & Mean & SD & Mean & SD \\
\hline Body weight $(\mathrm{g})^{*}$ & $37 \cdot 1$ & $2 \cdot 13$ & 37.9 & $2 \cdot 11$ & 37.0 & 2.37 & $36 \cdot 3$ & 2.44 \\
\hline Food intake $(\mathrm{g} / \mathrm{d})$ & 4.99 & 0.27 & 5.07 & 0.24 & $5 \cdot 21$ & 1.59 & $5 \cdot 12$ & 0.29 \\
\hline Stomach weight $(\mathrm{g}) \dagger$ & 0.31 & 0.02 & 0.31 & 0.02 & 0.31 & 0.02 & 0.29 & 0.03 \\
\hline Stomach mucosal weight $(\mathrm{g}) \dagger$ & 0.11 & 0.02 & $0 \cdot 12$ & 0.01 & $0 \cdot 13$ & 0.02 & 0.11 & 0.06 \\
\hline Ratio of mucosal weight:stomach weight† & 0.37 & 0.05 & 0.38 & 0.01 & 0.41 & 0.05 & 0.40 & 0.06 \\
\hline $\mathrm{pH}$ of the stomach contents $t$ & 4.0 & 0.1 & 2.9 & 1.0 & $3 \cdot 3$ & $1 \cdot 1$ & $2 \cdot 1$ & 1.2 \\
\hline Length of the small intestine $(\mathrm{cm})$ & $34 \cdot 1$ & 4.52 & 35.4 & $6 \cdot 15$ & $35 \cdot 7$ & 5.08 & 31.1 & 3.63 \\
\hline Caecal weight $(\mathrm{g})$ & 0.14 & 0.01 & 0.15 & 0.02 & 0.16 & 0.04 & 0.17 & 0.02 \\
\hline Caecal content weight (g) & 0.31 & 0.06 & 0.43 & $0 \cdot 16$ & 0.39 & $0 \cdot 12$ & 0.39 & 0.08 \\
\hline Length of the colon $(\mathrm{cm})$ & $8 \cdot 1$ & 0.68 & $7 \cdot 7$ & 0.78 & $8 \cdot 3$ & 1.28 & $8 \cdot 1$ & 1.71 \\
\hline Colon weight $(\mathrm{g})$ & 0.36 & 0.07 & 0.38 & 0.05 & 0.33 & 0.04 & 0.34 & 0.03 \\
\hline Colon content weight $(\mathrm{g})$ & 0.56 & 0.14 & 0.46 & 0.20 & 0.45 & 0.06 & 0.38 & 0.14 \\
\hline
\end{tabular}



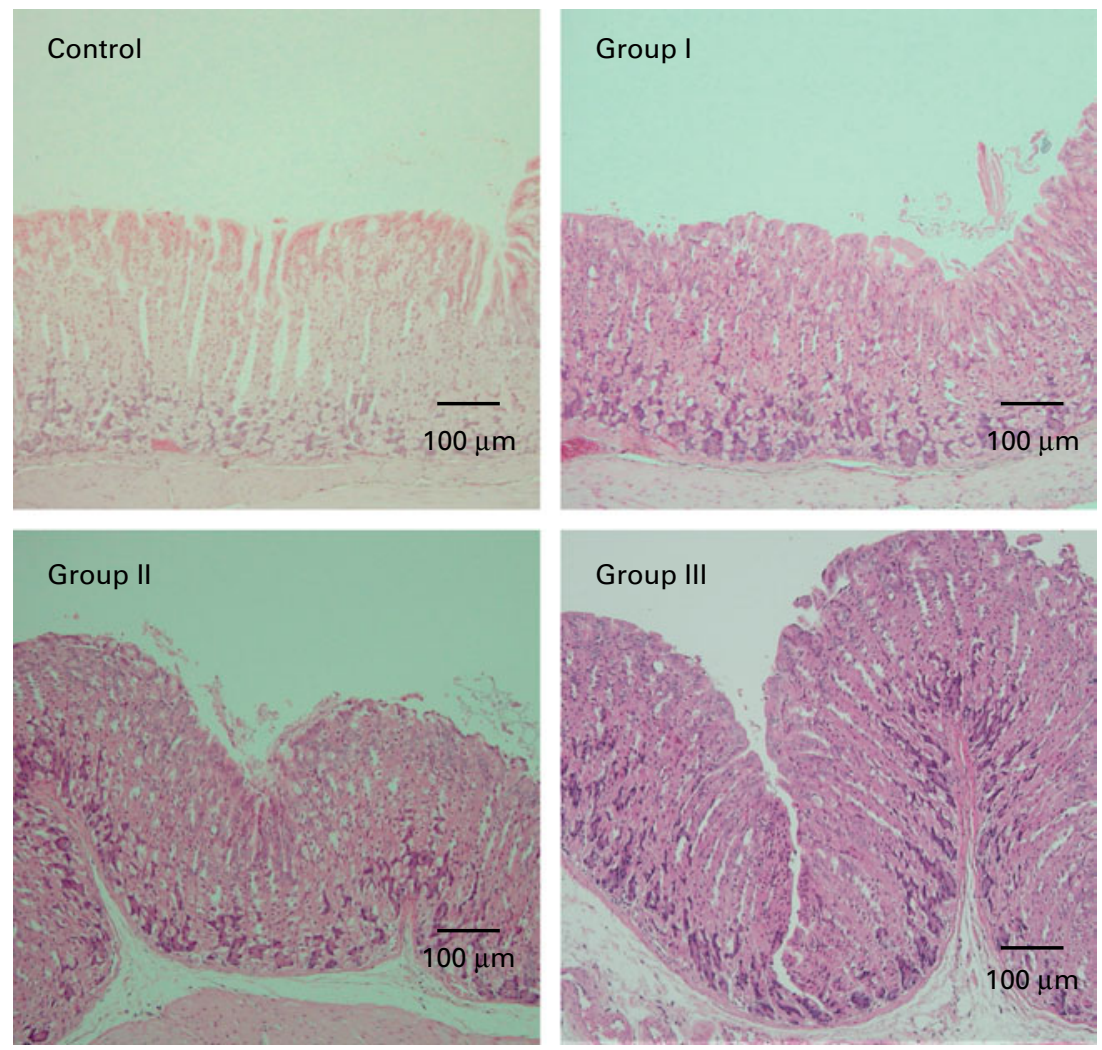

Fig. 1. Photomicrographs of mouse stomach samples (haematoxylin and eosin staining). Control, $0.2 \mathrm{ml}$ of water/d for 4 weeks; groups I, II and III, $0.2 \mathrm{ml}$ of methyl cellulose solution/d for 2, 3 and 4 weeks, respectively.
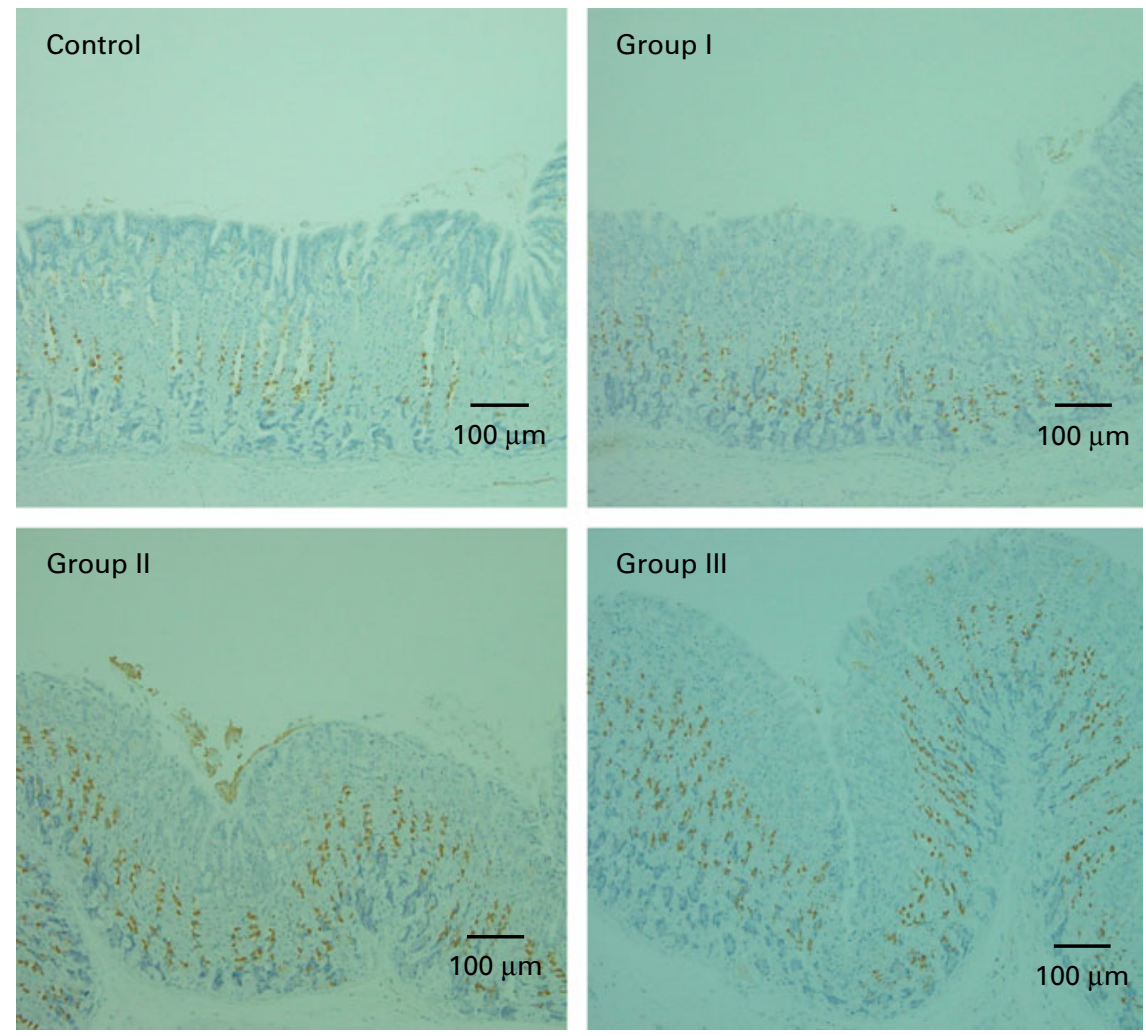

Fig. 2. Photomicrographs of mouse stomach samples (immunostained with the HIK1083 antibody). Control, $0.2 \mathrm{ml}$ of water/d for 4 weeks; groups I, II and III, $0.2 \mathrm{ml}$ of methyl cellulose solution/d for 2, 3 and 4 weeks, respectively. Brown colour indicates the HIK1083-stained area. 
Table 2. Gastric mucosal thickness, percentage of HIK1083 antibody-positive cells and amount of 8-oxo-2'-deoxyguanosine (8-oxodG) (Mean values and standard deviations)

\begin{tabular}{|c|c|c|c|c|c|c|c|c|}
\hline & \multicolumn{2}{|c|}{ Control } & \multicolumn{2}{|c|}{1} & \multicolumn{2}{|c|}{ II } & \multicolumn{2}{|c|}{ III } \\
\hline & Mean & SD & Mean & SD & Mean & SD & Mean & SD \\
\hline Thickness of the gastric mucosa $(\mu \mathrm{m}) \dagger$ & $357 \cdot 31$ & 23.9 & 364.58 & 54.7 & $447 \cdot 49^{\star}$ & $55 \cdot 0$ & $458 \cdot 81^{*}$ & $52 \cdot 1$ \\
\hline HIK1083-stained area (\%)‡ & 0.68 & 0.39 & $3 \cdot 80^{*}$ & 1.71 & $5 \cdot 04^{\star}$ & 2.03 & $6 \cdot 52^{\star}$ & 3.07 \\
\hline 8-OxodG§ & 0.341 & 0.044 & 0.341 & 0.053 & 0.411 & 0.109 & 0.459 & 0.079 \\
\hline
\end{tabular}

Control, $0.2 \mathrm{ml}$ of water/d for 4 weeks; groups I, II and III, $0.2 \mathrm{ml}$ of methyl cellulose solution/d for 2,3 and 4 weeks, respectively.

${ }^{*}$ Mean values were significantly different compared with the control group $(P<0.01)$.

$\dagger$ Values represent the mean of five mice. The average value of mucosal thickness taken at 150 points in the corpus ventriculi was calculated for each mouse.

$\ddagger$ Mean values represent the average of twenty-two to fifty-seven measurements of three mice selected randomly from five mice in each group.

$\S$ Values represent the mean of seven mice and are expressed as the molar ratio to $10^{5} 2^{\prime}$-deoxyguanosine.

Japanese - 2010' (http://www0.nih.go.jp/eiken/info/dpf/dris 2010en.pdf), in which dietary fibre intakes of more than $19.0 \mathrm{~g} / \mathrm{d}$ (for males) and $17.0 \mathrm{~g} / \mathrm{d}$ (for females) are recommended. It has therefore been estimated that ingestion of $320 \mathrm{ml}$ of viscous MC solution/d for humans is safe.

Gastric mucosal thickness was investigated by haematoxylin and eosin staining of tissue slices. Previous studies have calculated an average value of gastric mucosal thickness by measuring the thickness at $60-180$ arbitrarily selected points ${ }^{(2,22,23)}$. In the present study, mucosal thickness was only measured in the corpus ventriculi at 150 points because mucosal thickness varies depending on which part of the stomach is studied; the mucosa is thin in the pyloric region, and there is no mucosa in the proventriculus. The data show that the increase in gastric mucosal thickness takes place essentially between weeks 2 and 3 of MC intake. It is thought that thickening of the mucosa is caused by an increase in the number of cells that constitute the gastric tissue, because mucosal histology was not observed to change. Piel et al. ${ }^{(15)}$ and Tanabe et $a l{ }^{(16)}$ have reported that administration of dietary fibre increases the number of goblet cells in the small intestine. They suggested that the increase in gastrointestinal mucous resulted from an increase in the number of excretory cells. Satchithanandam et al. ${ }^{(22,23)}$ reported that dietary fibre feeding increased not only the amount of small-intestinal mucin but also the amount of gastric mucin. It was therefore presumed that a similar phenomenon (increasing the number of excretory cells) also occurred in the stomach.

To clarify this, we carried out HIK1083 immunohistochemical staining. The epitope that reacts with HIK1083 is a mucinous carbohydrate chain whose non-reduced end is connected to $N$-acetylglucosamine in the $\alpha$ form $^{(24)}$; this epitope is common to different species of vertebrates ${ }^{(25)}$. In the present study, most of the secreted mucous was removed in the process of preparing the specimen for analysis; thus, the part of the tissue that was stained with the HIK1083 antibody indicated gland mucous cells. The size of the stained area significantly increased with the duration of MC solution administration (Table 2), as can be seen in Fig. 2. This result suggests that an increase in gastric mucosal thickness is associated with an increase in the number of gland mucous cells. Montagne et al. ${ }^{(11)}$ and Satchithanandam et al. ${ }^{(22,23)}$ have suggested that an increase in intestinal mucin secretion is an adaptation to chronic mechanical irritation by the digesta containing dietary fibre. Furthermore, some reports have suggested that a rheological interaction between soluble dietary fibre macromolecules and mucin is important. Rossi et $a l^{(26)}$ reported that the interaction between a gelated polymer and gastrointestinal mucin was produced by the interpenetration of these molecules. Wapnir et al. ${ }^{(27)}$ and Go et $a{ }^{(28)}$ reported that contact of a $0 \cdot 25-1 \%(\mathrm{w} / \mathrm{v})$ solution of MC or carboxymethylcellulose with the mucosal surface could lengthen the glycocalyx of gastrointestinal mucus. Because the concentration of the viscous MC solution used in the present study was $0.5 \%(\mathrm{w} / \mathrm{v})$, there might be an interaction between this solution and the gastric mucosal surface. Schmidt-Witting et al. ${ }^{(29)}$ reported that an inflammatory reaction is associated with an increase in mucinous cells. Matsuzawa et $a l .{ }^{(30)}$ and Kaneko et al. ${ }^{(31)}$ reported that the secretion of gastric gland mucin was increased by Helicobacter pylori infection, which induced significant inflammation in the gastric mucosa. However, neutrophil invasion, which is both a sign of inflammation and the main source of reactive oxygen species, was not observed in gastric tissue in the present study (Fig. 1). Moreover, there was no significant increase in 8-oxodG in the groups administered with viscous MC solution compared with the control group. Mechanisms other than inflammation that induce an increase in the number of gland mucous cells should be further investigated.

\section{Acknowledgements}

We express our sincere appreciation to Dr Noboru Harada, Emeritus Professor of Gastrointestinal Surgery of University of Shizuoka, for his critical review of the histological examination. The present study was supported by a grant from the University of Shizuoka. F. T. designed the experiments, carried out the main experimental work and wrote the manuscript. H. S. carried out the 8-oxodG measurement experiment. Both authors declare that they have no personal or financial conflict of interest.

\section{References}

1. World Health Organization (1990) Toxicological Evaluation of Certain Food Additives and Contaminants. WHO Food Additives Series no. 26. Geneva: WHO.

2. Irwin RD (2006) NTP technical report on the comparative toxicity studies of allyl acetate (CAS no. 591-87-7), allyl 
alcohol (CAS no. 107-18-6) and acrolein (CAS no. 107-02-8) administered by gavage to $\mathrm{F} 344 / \mathrm{N}$ rats and $\mathrm{B} 6 \mathrm{C} 3 \mathrm{~F} 1$ mice. Toxic Rep Ser 48, 1-73, A1-H10.

3. Langhout DJ, Schutte JB, Jong JD, et al. (2000) Effect of viscosity on digestion of nutrients in conventional and germ-free chicks. Br J Nutr 83, 533-540.

4. McDonald DE, Pethick DW, Mullan BP, et al. (2001) Increasing viscosity of the intestinal contents alters small intestinal structure and intestinal growth, and stimulates proliferation of enterotoxigenic Escherichia coli in newly-weaned pigs. Br J Nutr 86, 487-498.

5. Van Nevel CJ, Dierick NA, Decuypere JA, et al. (2006) In vitro fermentability and physicochemical properties of fibre substrates and their effect on bacteriological and morphological characteristics of the gastrointestinal tract of newly weaned piglets. Arch Anim Nutr 60, 477-500.

6. Vissia GHP \& Beynen AC (2000) Inhibitory effect of dietary carboxymethylcellulose on fat digestibility in rats fed diets containing either starch or glucose. Anim Feed Sci Technol 85, 139-144.

7. Dikeman CL, Murphy MR \& Fahey GC (2006) Dietary fibers affect viscosity of solutions and stimulated human gastric and small intestinal digesta. J Nutr 136, 913-919.

8. Hopwood DE, Pethick DW \& Hampson DJ (2002) Increasing the viscosity of the intestinal contents stimulates proliferation of enterotoxigenic Escherichia coli and Brachyspira pilosicoli in weaner pigs. Br J Nutr 88, 523-532.

9. Montagne L, Cavaney FS, Hampson DJ, et al. (2004) Effect of diet composition on postweaning colibacillosis in piglets. J Anim Sci 82, 2364-2374.

10. Lalles JP, Boudry G, Favier C, et al. (2006) High-viscosity carboxymethylcellulose reduces carbachol-stimulated intestinal chloride secretion in weaned piglets fed a diet based on skimmed milk powder and maltodextrin. Br J Nutr 95, 488-495.

11. Montagne L, Piel C \& Lalles JP (2004) Effect of diet on mucin kinetics and composition: nutrition and health implications. Nutr Rev 62, 105-114.

12. Morita T, Tanabe $\mathrm{H}$, Ito $\mathrm{H}$, et al. (2008) Long-term ingestion of insoluble dietary fiber increases luminal mucin contents, but has no effect on nutrient absorption in rats. Biosci Biotechnol Biochem 72, 767-772.

13. Morita $\mathrm{T}$, Tanabe $\mathrm{H}$, Ito $\mathrm{H}$, et al. (2006) Increased luminal mucin does not disturb glucose or ovalbumin absorption in rats fed insoluble dietary fiber. J Nutr 136, 2486-2491.

14. Tanabe H, Ito H, Sugiyama K, et al. (2006) Dietary indigestible components exert different regional effects on luminal mucin secretion through their bulk-forming property and fermentability. Biosci Biotechnol Biochem 70, 1188-1194.

15. Piel C, Montagne L, Seve B, et al. (2004) Increasing digesta viscosity carboxymethylcellulose in weaned piglets stimulates ileal goblet cell numbers and maturation. J Nutr 135, 86-91.

16. Tanabe H, Sugiyama K, Matsuda T, et al. (2005) Small intestinal mucins are secreted in proportion to the setting volume in water of dietary indigestible components in rats. $J$ Nutr 135, 2431-2437.
17. Diehl KH, Hull R, Morton D, et al. (2001) A good practice guide to the administration of substances and removal of blood, including routes and volumes. J Appl Toxicol 21, $15-23$.

18. Nakamura N, Ota H, Katsuyama T, et al. (1998) Histochemical reactivity of normal, metaplastic, and neoplastic tissues to alpha-linked $\mathrm{N}$-acetylglucosamine residue-specific monoclonal antibody HIK 1083. J Histochem Cytochem 46, 793-801.

19. Hayashida H, Ishihara K, Ichikawa T, et al. (2001) Expression of a specific mucin type recognized by monoclonal antibodies in the rat gastric mucosa regenerating from acetic acid-induced ulcer. Scand J Gastroenterol 36, 467-473.

20. Kaneko T, Tahara S \& Takabayashi F (2003) Suppression of lipid hydroperoxide-induced oxidative damage to cellular DNA by esculetin. Biol Pharm Bull 26, 840-844.

21. Eastwood MA, Brydin WG, Anderson DM, et al. (1990) The effects of dietary methylcellulose in man. Food Addit Contam 7, 9-19.

22. Satchithanandam S, Vargofcal-Apker M, Calvert RJ, et al. (1990) Alteration of gastrointestinal mucin by fiber feeding in rats. $J$ Nutr 120, 1179-1184.

23. Satchithanandam S, Klurfeld DM, Calvert RJ, et al. (1996) Effects of dietary fibers on gastrointestinal mucin in rats. Nutr Res 16, 1163-1177.

24. Ishihara K, Kurihara M, Goso Y, et al. (1996) Peripheral alpha-linked $N$-acetylglucosamine on the carbohydrate moiety of mucin derived from mammalian gastric gland mucous cells: epitope recognized by a newly characterized monoclonal antibody. Biochem J 318, 409-416.

25. Kurihara M, Ishihara K, Ota H, et al. (1998) Comparison of four monoclonal antibodies reacting with gastric gland mucous cell-derived mucins of rat and frog. Comp Biochem Physiol B Biochem Mol Biol 121, 315-321.

26. Rossi S, Bonferoni MC, Ferrari F, et al. (1996) Characterization of mucin interaction with three viscosity grades of sodium carboxymethylcellulose. Comparison between rheological and tensile testing. Eur J Pharm Sci 4, 189-196.

27. Wapnir RA, Wingertzahn MA \& Teichberg S (1997) Cellulose derivatives and intestinal absorption of water and electrolytes: potential role in oral rehydration solutions. Proc Soc Exp Biol Med 215, 275-280.

28. Go JT, Harper RG, Sia CG, et al. (1994) Oral rehydration solutions: increased water and sodium absorption by addition of viscosity-enhancing agent in a rat model of chronic osmotic diarrhea. J Pediatr Gastroenterol Nutr 19, 410-416.

29. Schmidt-Witting U, Enss ML, Coenen M, et al. (1996) Response of rat colonic mucosa to a high fiber diet. Ann Nutr Metab 40, 343-350.

30. Matsuzawa M, Ota H, Hayama M, et al. (2003) Helicobacter pylori infection up-regulates gland mucous cell-type mucins in gastric pyloric mucosa. Helicobacter 8, 594-600.

31. Kaneko T, Ota H, Hayama M, et al. (2000) Helicobacter pylori infection produces expression of a secretary component in gastric mucous cells. Virchows Arch 437, 514-520. 